\title{
MODELAGEM E SIMULAÇÃO DA SEPARAÇÃO DO FLUIDO DE PERFURAÇÃO EM PENEIRAS VIBRATÓRIAS
}

\author{
M. D. MARQUES ${ }^{1}$ e V. V. MURATA ${ }^{1}$ \\ ${ }^{1}$ Universidade Federal de Uberlândia, Faculdade de Engenharia Química \\ e-mail para contato: micheldornelas@ymail.com; valeria@ufu.br
}

\begin{abstract}
RESUMO - Esse trabalho apresenta a modelagem e simulação da separação entre sólidos e o fluido usado na perfuração de poços de petróleo em peneiras vibratórias. O modelo desenvolvido para a representação da passagem do fluido através da tela das peneiras utiliza uma analogia com o modelo de filtração baseado na análise das resistências. A resistência ao escoamento do fluido é considerada equivalente à condutância da tela da peneira. A queda de pressão através do meio filtrante e a viscosidade da lama formada pelo cascalho e pelo fluido de perfuração são parâmetros do modelo. A especificação da peneira considerada na simulação é a mesma da utilizada em campo: tela API140 com três camadas de espessura de $0,00069 \mathrm{~m}$. O fluxo de permeado é calculado considerando o efeito da porosidade e do diâmetro das partículas. E nota-se que quanto maior o diâmetro da partícula e maior porosidade, maior será a altura da torta sobre a tela.
\end{abstract}

\section{INTRODUÇÃO}

O fluido de perfuração utilizado na perfuração de poços de petróleo tem funções importantes como estabilização pneumática dos poços, resfriamento da broca e arraste de cascalho. O consumo deste fluido é expressivo e a legislação ambiental proíbe o seu descarte, exigindo processos eficientes de separação entre o cascalho e o fluido. $O$ peneiramento é a primeira etapa deste processo de separação e ocorre logo após o retorno do fluido à superfície. A eficiência do peneiramento é afetada por características da peneira e da lama formada pelo cascalho e pelo fluido, como densidade, parâmetros reológicos, teor de sólidos, temperatura e vazão.

O objetivo deste trabalho é desenvolver um modelo matemático representativo do processo de peneiramento do fluido de perfuração utilizado na perfuração de poços de petróleo, baseado em modelos de filtração em função de similaridades discutidas neste artigo. 


\section{CONCEITOS E FUNDAMENTAÇÃO TEÓRICA}

A modelagem do peneiramento proposta por King (2001) considera a cinética do processo, em que a taxa de transmissão do sólido através da tela da peneira é função do tipo de tela, da alimentação de sólidos, do tipo e do tamanho do sólido a ser peneirado. Outra abordagem é proposta por Li et al (2001), levando em consideração a ocorrência de vários tipos de movimentos e as interações que podem ocorrer entre as próprias partículas e entre as partículas e a tela. Ainda em King (2001), utiliza-se uma equação empírica em que a capacidade teórica é igual à capacidade básica da tela corrigida por parâmetros que se referem à tela e às partículas alimentadas. Nenhum destes modelos leva em consideração a presença de líquidos na alimentação da peneira, objeto deste estudo.

Para considerar a presença de líquidos na alimentação, o modelo de filtração baseado na análise das resistências é aplicado considerando a passagem do líquido através de uma membrana. A membrana é considerada equivalente à tela da peneira e os seus poros equivalentes aos dutos da peneira cujas dimensões são especificadas pelo seu mesh. O fenômeno é afetado por mútuas interações entre a tela e substâncias presentes no líquido, como abordado em Konieczny (2001).

No modelo de filtração baseado na análise das resistências, o fluxo volumétrico de permeado $\left(J_{v}\right)$ expresso pela Equação 1, sendo $\Delta P$ a queda de pressão através da membrana, seguido das resistências

$J_{v}=\frac{\Delta P}{\mu R_{\text {total }}}$

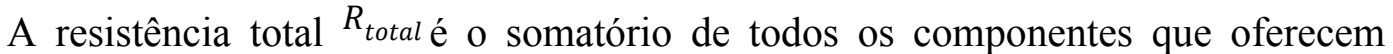
resistência à passagem do fluido: a resistência oferecida pela própria membrana $\left(R_{m}\right) \mathrm{e}$ a resistência proveniente da incrustação. A resistência ligada à incrustação tem duas componentes: a resistência que descreve a incrustação reversível $\left(R_{f 0}\right)$ e a resistência ligada à incrustação irreversível $\left({ }^{R} f n\right)$, conforme apresentado na Equação 2:

$R_{\text {total }}=R_{m}+R_{f 0}+R_{f n}$

No processo de separação do fluido de perfuração, observa-se a formação de torta na parte inicial da tela, próxima ao ponto de alimentação da lama, como apresentado de forma esquemática na Figura 1.

Figura 1 - Esquema da região da formação de torta na parte inicial da peneira de separação entre fluido de perfuração e cascalho 


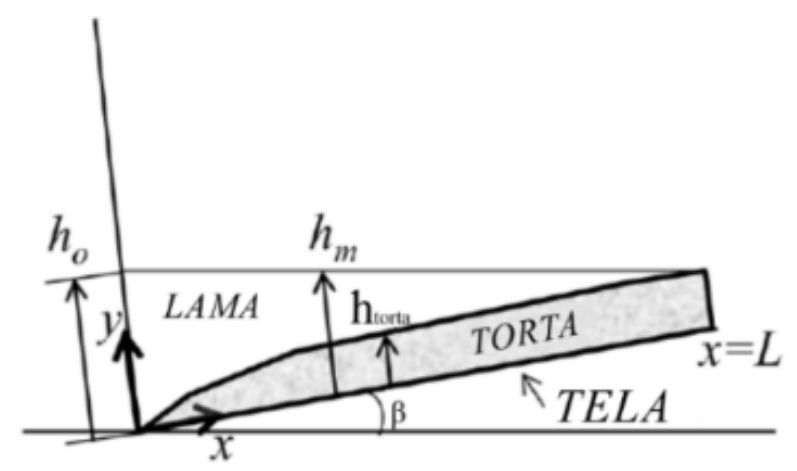

Conforme proposto por Raja e Chase (2010), a razão entre a taxa de crescimento volumétrico da torta $\left({ }^{\text {torta }}\right.$ e o fluxo volumétrico de filtrado $\left({ }{ }_{\text {torta }}\right)$ pode ser expresso pela Equação 3, em função da fração volumétrica de líquido da torta $\varepsilon^{L}$ e da lama $\varepsilon^{m}$ :

$\frac{V_{\text {torta }}}{Q_{\text {torta }}}=\frac{1-\varepsilon^{m}}{\varepsilon^{m}-\varepsilon^{L}}$

Definindo $\dot{V}_{\text {torta e }} Q_{\text {torta em um elemento }} \Delta x$ da peneira pela Equação 4 e pela Equação 5 respectivamente:

$\dot{V}_{\text {torta }}=b \Delta x \frac{d h_{\text {torta }}}{d t}$

$Q_{\text {torta }}=-b \Delta x \varepsilon^{L} v_{y}^{L}$

No qual $b$ é a largura da tela, $h_{\text {torta }}$ a altura da torta $\mathrm{e}^{v_{y}^{L}}$ é a velocidade de líquido na direção y. Assim, substituindo-se as Equações 4 e 5 na Equação 3, tem-se a Equação 6:

$\frac{d h_{\text {torta }}}{d t}=-\frac{\varepsilon^{L} v_{y}^{L}\left(1-\varepsilon^{m}\right)}{\varepsilon^{m}-\varepsilon^{L}}$

A variação da altura da torta $h_{\text {torta }}$ com a posição na tela pode ser escrita conforme a Equação 7, admitindo por hipótese que o sólido carrega o líquido na direção x com a mesma velocidade ao longo da tela:

$\frac{d h_{\text {torta }}}{d x}=-\frac{\varepsilon^{L} v_{y}^{L}\left(1-\varepsilon^{m}\right)}{v_{x}^{S}\left(\varepsilon^{m}-\varepsilon^{L}\right)}$

No qual $v_{x}^{S}$ é a velocidade do sólido na direção $\mathrm{x}$. 
A condição inicial adotada considera que no instante zero, quando se inicia a alimentação da lama, não há formação de torta.

A velocidade de líquido na direção y através da torta é calculada pela Equação (8):

$v_{y}^{L}=\frac{-g \cos \beta\left(\rho^{L}\left(h_{\text {torta }}+h_{\text {tela }}\right)+\rho^{m}\left(h_{m}-h_{\text {torta }}\right)\right)}{\varepsilon^{L} \mu v_{y}^{L}\left(\frac{h_{\text {torta }}}{k_{\text {torta }}}+\frac{h_{\text {tela }}}{k_{\text {tela }}}\right)}$

$\rho^{m}=\varepsilon^{m} \rho^{L}+\left(1-\varepsilon^{m}\right) \rho^{s}$

$h_{m}=h_{0}-x \tan \beta$

$k_{\text {torta }}=\frac{(\bar{d} p \phi)^{2} \varepsilon^{3}}{90(1-\varepsilon)^{2}}$

A vazão total de fluido na área em que ocorre a torta é calculada pela Equação 12:

$Q=b \int_{0}^{L} \varepsilon^{L} v_{y}^{L} d x$

Sendo L o comprimento onde $h_{m}=h_{\text {torta }}$.

Portanto, o modelo matemático proposto é formado pelas Equações 1, 2, 10 e 12 quando aplicado permite calcular vazão total de fluido $(Q)$, altura da lama $\left(h_{m}\right)$, altura da torta $\left(h_{\text {torta }}\right)$ e velocidade de líquido na direção y $\left(v_{y}^{L}\right)$.

\section{Simulação}

A peneira vibratória considerada na modelo tem tela API140 que consiste em três camadas de malha de espessura 0,00069 metros e inclinação de $3^{\circ}$. O fluido de perfuração é alimentado à taxa de $45,36 \mathrm{~kg} / \mathrm{s}$ e a torta formada move-se ao longo da tela e tem permeabilidade e porosidade características. O movimento vibratório da tela é elíptico com componentes vertical e horizontal. Outros parâmetros são apresentados na Tabela 1.

Tabela 1 - Parâmetros do modelo matemático

\begin{tabular}{|c|c|c|}
\hline & Parâmetro & Valor \\
\hline$h_{0}$ & Altura inicial de lama & $0,0505 \mathrm{~m}$ \\
\hline$h_{\text {tela }}$ & Espessura da tela & $0,00069 \mathrm{~m}$ \\
\hline$k_{\text {tela }}$ & Permeabilidade da tela & $2,5762 \mathrm{e}-10 \mathrm{~m}^{2}$ \\
\hline$h_{\text {tela }}$ & Espessura da tela & $0,00069 \mathrm{~m}$ \\
\hline$\rho^{L}$ & Densidade do fluido & $1100 \mathrm{~kg} / \mathrm{m}^{3}$ \\
\hline$\rho^{S}$ & Densidade dos sólidos & $2600 \mathrm{~kg} / \mathrm{m}^{3}$ \\
\hline
\end{tabular}




\begin{tabular}{|c|c|c|}
\hline$\mu$ & Viscosidade da lama & $0,024 \mathrm{~kg} / \mathrm{m} . \mathrm{s}$ \\
\hline$v_{x}^{S}$ & Velocidade da torta na direção $\mathrm{x}$ & $0,10688 \mathrm{~m} / \mathrm{s}$ \\
\hline
\end{tabular}

O modelo é resolvido de forma numérica utilizado o método de Runge-Kutta através do software Maple $15^{\circledR}$.

\section{Resultados e Discussão}

Os gráficos na Figura 3 mostram a altura da lama $\left(h_{m}\right)$, a altura da torta ao longo da tela $\left(h_{\text {torta }}\right)$ para diferentes diâmetros de partículas $(60 \mu, 100 \mu$ e $300 \mu)$, e porosidade de 0,$3 ; 0,35 ; 0,4 ; 0,45$ e 0,5 .

Figura 1 - - Efeito do diâmetro da partícula alimentada na lama de perfuração sobre a altura da torta formada sobre a peneira
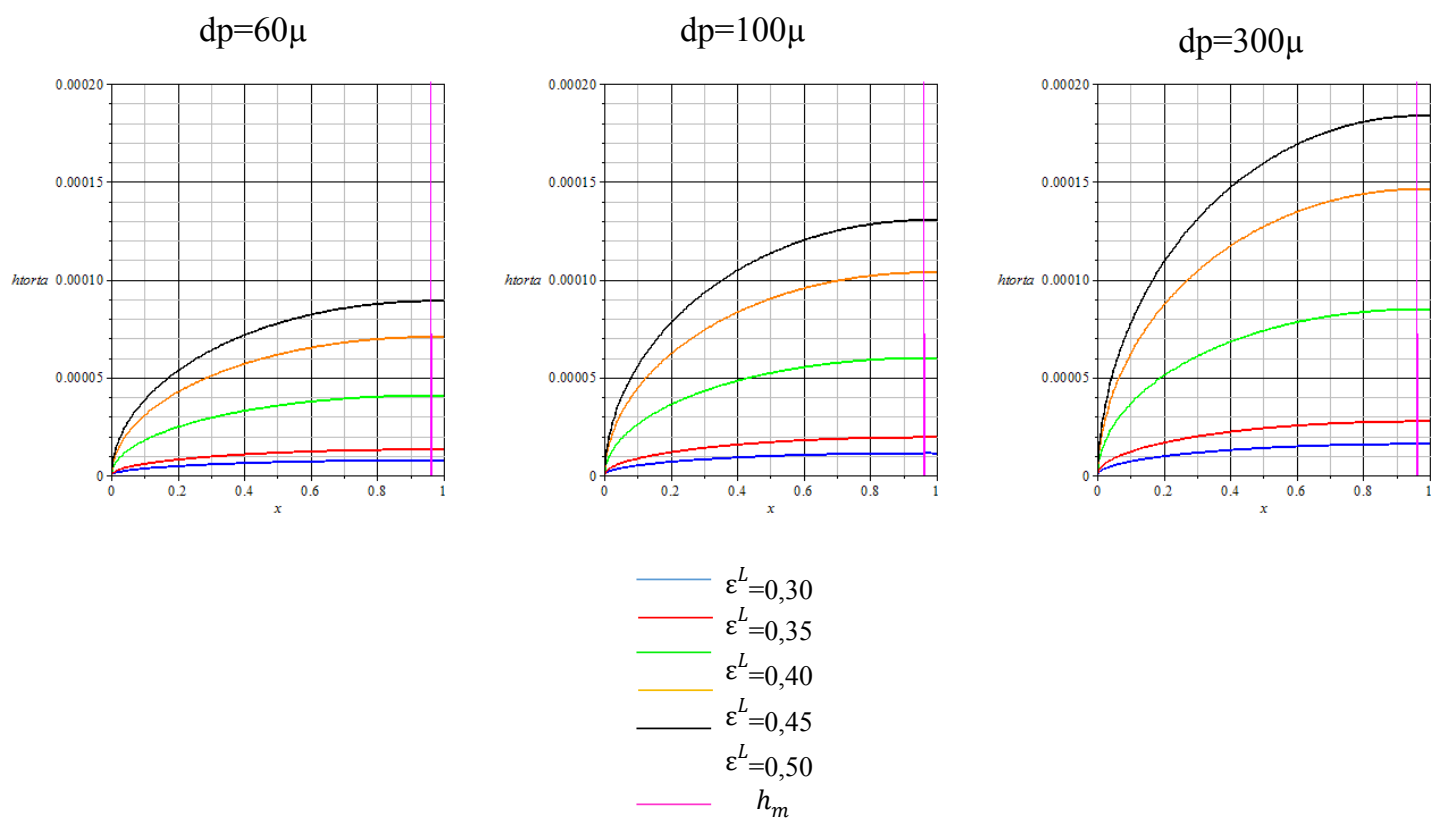

A partir dos gráficos da Figura 3, afirma-se que à medida que o diâmetro da partícula aumenta, o perfil da altura da torta tende a alcançar uma altura maior, isso pode ser explicado pelo fato que partículas com maiores diâmetros formam uma camada maior de torta, devido seu maior volume. Esse efeito ocorre para porosidades menores também, porém, em menor proporção, logo o efeito do aumento do diâmetro é minimizado por tortas com menor porosidade. Além disso, nota-se que a interseção das curvas com reta de $h_{m}$ é dada praticamente no mesmo comprimento $x$, ou seja, a variação do diâmetro não afeta $o$ comprimento de tela requerido para formação de torta. 


\section{Conclusão}

O modelo foi simulado com sucesso, porém a validação do modelo exige experimentação para relacionar os resultados apresentados da simulação com os dados reais a fim de verificar a influência de outros parâmetros.

\section{REFERÊNCIAS}

CHASE, G.G.; WILLIS, M.S. Compressive Cake Filtration. Chemical Engineering Science. 47(6). 1373-1381. 1992.

KING, R.P. Modelling and Simulation of Mineral Processing Systems. Butterworth Heinemann. Oxford. 2001.

KONIECZNY, K. Modeling of membrane filtration of natural water for potable purposes. Desalination. 143. 123-139. Elsevier. 2002.

LI, J. et al. Discrete particle motion sieves: A numerical study using the DEM simulation. Elsevier. Powder Technology. 2003. 